\title{
CONCERTAÇÃO E PODER \\ O agronegócio como fenômeno político no Brasil
}

\section{Caio Pompeia (1)}

\author{
(D) https://orcid.org/0000-0002-1692-1985 \\ (1) Universidade de São Paulo (USP), São Paulo - SP, Brasil. Email: caporine@gmail.com \\ DOI: $10.1590 / 3510410 / 2020$
}

\section{Introdução}

Agentes políticos relacionados ao agronegócio inseriram-se centralmente na agenda pública nacional, na década de 2010, aprofundando um pacto de economia política (Delgado, 2012) que visa à expansão de seu domínio sobre terras, parte considerável delas públicas (Almeida, 2010). Notória, essa ênfase patrimonialista tem resultado em contestaçóes aos direitos territoriais de povos indígenas, populações tradicionais e camponeses (Carneiro da Cunha, 2018), afora outras açóes, como aquelas relacionadas à questáo ambiental. O presente artigo se dedica a analisar um dos fatores preponderantes para o fortalecimento desse poder: a crescente convergência política no campo do agronegócio.

Artigo recebido em: 30/08/2019

Aprovado em: 14/01/2020
Tal movimento de aproximação, a ser demonstrado no trabalho aqui apresentado, engendra, sobretudo durante os anos 2010, um novo padrão nas relações entre os agentes privados, e deles com o Estado. Como apontam Graziano da Silva $(1991 ; 2010)$ e Bruno (2017), o processo de industrialização da agricultura promoveu, ao gerar condiçóes para a constituição de complexos agroindustriais (CAIs) (Kageyama et al., 1990), um reordenamento das formas de atuação política no campo do agronegócio. Com a especialização produtiva nessa etapa de modernização, o sindicalismo patronal, típico do primeiro padrão, conforme Graziano da Silva (1991), perdeu espaço para as associaçóes por produto e para as cooperativas, às quais se somaram, posteriormente, entidades intersetoriais (Mendonça, 2008) - dando, assim, conformação a um segundo padrão na representação de interesses no referido campo (Graziano da Silva, 1991).

O que se identifica, aqui, como terceiro padrão da representatividade é, pois, um impulso 
organizado e sistemático, em função da agudização de disputas fundiárias e conflitos socioambientais, da orquestração política no campo do agronegócio. Essa convergência crescente não significa retorno à unidade de representação, marcante no primeiro padrão, nem reverte a multiafiliação, notável no segundo. Diferentemente, reposiciona ambas em uma nova estrutura de ação política, mais apta a tratar de questôes amplas, como a indígena, a ambiental, a agrária, a trabalhista e a alimentar. Esse reposicionamento - em que coexistem elementos organizacionais típicos dos três padrōes - será evidenciado ao longo deste trabalho.

Para atribuir maior inteligibilidade a essa nova conformação de ação política e operacionalizar a análise empreendida sobre ela, utiliza-se, no presente estudo, o conceito de concertação política do agronegócio. O sentido de concertação aqui adotado tem conexão tanto com características etimológicas do termo, quanto com sua mobilização na literatura científica. Em latim, concertatio - e as demais palavras da mesma família - referia-se a ocasiões nas quais adversários debatiam e disputavam posiçóes entre si (Tachard, 1687 , p. 274). Nas acepçóes contemporâneas, em línguas como francês, inglês e português, o termo foi paulatinamente inflexionado, passando a remeter a circunstâncias de cooperação e consultas voltadas à produção de acordos. Aceitando, provisoriamente, entendimento que sintetize os sentidos descritos acima, tem-se a concertação como situação na qual agentes em oposição procuram racionalizar suas diferenças com vistas a encontrar consensos.

Em seguida, é fundamental identificar de quais "agentes em oposição" se está a tratar com o uso do termo. Para cumprir esse objetivo, reporta-se a pesquisas da economia e sociologia rural. Baseando-se em Moyano (1985), pioneiro na área a utilizar a expressão, Graziano da Silva mobiliza a ideia de concertação no âmbito de análise política dos CAIs (Graziano da Silva, 1991). Assumindo o complexo como fenômeno determinado a cada conjuntura histórica, o autor apresenta-o como desdobramento de uma "concertação" entre, de um lado, múltiplos interesses privados, e, de outro, aqueles estatais (Graziano da Silva, 1991, p. 21-23).

Adotando-se, em acordo com Graziano da Silva, o caráter público-privado do termo, resta compreender as formas de operação que são atribuídas às situações de concertação. Para isso, recorre-se a cientistas políticos. Doner e Compston identificam nela um elevado grau de organização tanto dos atores privados, quanto dos públicos, além de sistematicidade e alta institucionalização nas relaçóes entre ambos (Doner, 1991; Compston, 2003). Apoiado em tais características, Doner aponta a concertação como uma forma forte de coalizão.

Com fundamento nessas definiçóes sobre o termo, na literatura citada anteriormente e nas observaçóes durante o trabalho de campo, o presente artigo apreende a concertação política como uma configuração historicamente situada de relaçôes de convergência no campo do agronegócio. Suas principais características são: a intersetorialidade, ${ }^{1}$ a abrangência privado-estatal, a multilateralidade, ${ }^{2}$ a elevada institucionalização, e a sistematicidade nas interaçóes.

Essas interaçóes ocorrem em três níveis principais: (1) entre entidades, na conformação de núcleos intersetoriais ampliados, como o Instituto Pensar Agropecuária (IPA) e o bloco Confederação da Agricultura e Pecuária do Brasil/Conselho das Entidades do Setor Agropecuário (CNA/Conselho do Agro); (2) entre essas nucleaçóes amplas; e (3) entre tais núcleos e determinados agentes do Estado, ${ }^{3}$ a exemplo da Frente Parlamentar Mista da Agropecuária (FPA) e do Ministério da Agricultura, Pecuária e Abastecimento (Mapa).

Por meio de dispositivos de convergência mobilizados nesses diversos níveis da concertação política do agronegócio, os agentes ampliam a racionalização de suas diferenças, competiçóes e conflitos com o propósito de negociar acordos que facilitem, de um lado, a agregação de representatividade, recursos financeiros e saberes técnicos, e, de outro, a atuação política conjunta em relação à opinião pública e ao Estado.

Para ampliar o que Fraser chama de capacidade de tradução, aludindo à força para transformar pleitos em mudanças legislativas e poder administrativo (Fraser, 2014), os agentes da concertação operam um aparato de justificação na esfera pública. ${ }^{4}$ Com inspiração na sociologia pragmática francesa (Boltanski \& Chiapello, 2005; Boltanski \& Thévenot, 2006), entende-se o 
referido aparato como um conjunto de proposiçóes que, fundamentando um imaginário - ou um "espírito", nas palavras dos autores - relacionado ao agronegócio no Brasil, contribuem para justificar os agentes da concertação e encorajam, por desdobramento, endosso de parcela da opiniâo pública às suas pautas políticas e apoio da cúpula do Estado a elas.

Não obstante sua eficácia, tal aparato apresenta relevantes simulaçôes, que se baseiam em indistinção entre as dimensôes política e analítica do campo do agronegócio. Totalizadora, a noção cunhada nos Estados Unidos, e posteriormente consolidada como categoria no Brasil, engloba toda a agropecuária e a totalidade da ampla relação de funçóes situadas a montante e jusante dela (ver Davis, 1955; Davis \& Goldberg, 1957; Bittencourt de Araújo; Wedekin; Pinazza, 1990; Centro de Estudos Avançados em Economia Aplicada, 2017). Entretanto, nos núcleos da concertação tomados em conjunto, parte considerável dessas funçóes não se faz presente, podendo-se citar, dentre os déficits mais relevantes, tanto as redes varejistas e atacadistas, quanto os restaurantes e estabelecimentos que servem comida, além da maior parte das representaçóes não patronais da agropecuária e de porção relevante das indústrias de alimentos (Pompeia, 2018; 2020).

Apesar desses déficits, líderes da concertação operam sinédoques políticas - açóes deliberadas que provocam confusóes entre partes e totalidades - ao agenciar estatísticas macroeconômicas baseadas na categoria agronegócio para passar a impressão pública de que representam muito mais agentes econômicos do que de fato o fazem. Ou seja, ao projetar indistinção entre as dimensóes analítica (totalizadora) e política (menos abrangente) do campo do agronegócio, o que se procura, portanto, por meio da sinédoque, é simular uma representatividade superdimensionada para a opinião pública e o Estado. ${ }^{6}$

$\mathrm{O}$ artigo está dividido em três partes: na primeira, apresenta-se exame lógico-histórico dos modos como a concertação se consolidou no processo político nacional e mobilizou um aparato de justificação para atuar em relação a grandes questóes nacionais; na segunda, atenta-se aos conflitos e competiçóes existentes em seus diversos níveis; por fim, na terceira, estudam-se os dispositivos empregados em seu âmbito para administrar oposiçóes, produzir consensos e maximizar a eficácia política.

A análise tem sua fundamentação principal em pesquisa de campo, composta pelo acompanhamento sistemático - durante o período de oito meses (de dezembro de 2018 a julho de 2019) - de núcleos do campo do agronegócio e pela realização de trinta e oito entrevistas com líderes empresariais e políticos. Os principais espaços nos quais se fez o trabalho de campo foram o IPA, o Congresso Nacional e a CNA. Dentre os entrevistados, podem-se destacar três conjuntos: dirigentes de associaçôes, parlamentares e ministros.

\section{Concertação e justificaçóes: a ação política para incidir em temas amplos}

Ainda na segunda metade dos anos 2000, disputas crescentes com o governo federal e setores progressistas da sociedade civil relacionadas às questóes agrícola, agrária, ambiental, indígena e trabalhista haviam levado a Associação Mato-grossense do Algodão (Ampa) e a Associação dos Produtores de Soja e Milho de Mato Grosso (Aprosoja-MT) ${ }^{7}$ a ampliarem suas ações no Congresso Nacional. Nessa mobilização, elas aproximaram-se de modo mais sistemático de parlamentares da FPA, que, por seu turno, também demandavam maior apoio empresarial (Pompeia, 2018).

Intensificava-se, à época, o fenômeno que a literatura passou a intitular de land grabbing, ou escalada global da apropriaçáo de terras (Sauer; Borras Jr., 2016), movimento estimulado, em parte relevante, pela maior demanda global por commodities agropecuárias e seu acentuado aumento de preços (Sauer; Leite, 2012; Flexor; Leite, 2017). Não por acaso, em São Paulo, fóruns do agronegócio com participação predominante de indústrias - como a Associação Brasileira do Agronegócio (Abag) e o Conselho Superior do Agronegócio (Cosag), da Federação das Indústrias do Estado de São Paulo (Fiesp) - inflexionavam suas cartas programáticas para questionar as Terras Indígenas (TIs) e as Unidades de Conservação (UCs) (ver Abag, 2010).

No processo de aumento dos interesses de agentes privados por novas áreas no Brasil, a dispersão política 
no campo do agronegócio - que prevalecera durante as décadas seguintes à fase de industrialização da agricultura, conforme identifica Graziano da Silva (2010) - começou a refluir. Estando a reforma agrária fora da agenda governamental (Pompeia, 2018), o impulso substancial de ordem prática para essa inflexão - a qual pode ser considerada marco para a consolidação da concertação política do agronegócio - foram os embates em torno do Código Florestal no início da década de 2010. Com o objetivo principal de anistiar desmatadores e reduzir previsóes de proteção ambiental desse Código, representantes do setor secundário, liderados por entidades como a União da Indústria de Cana de Açúcar (UNICA), aproximaram-se do núcleo parlamentar que a Ampa e a Aprosoja-MT vinham impulsionando.

Em 2011, o trio agricultura-indústria-Parlamento daria materialidade ao IPA, na primeira manifestação decisiva para o surgimento do terceiro padrão de representação no campo do agronegócio, como apontado na Introdução. Com forte sustentação das distintas entidades presentes nesse fórum - além da atuação da CNA, presidida, à época, pela senadora Kátia Abreu (então afiliada ao Partido Social Democrático, por Tocantins) -, a FPA administrou suas diferenças internas e conseguiu agir de forma concertada para alterar substancialmente o Código Florestal (Pompeia, 2018) e, ato contínuo, focar suas atençóes na contestação dos direitos territoriais indígenas e de populaçôes tradicionais (Carneiro da Cunha, 2018).

Embora a terceira parte do presente artigo analise detidamente as tecnologias organizacionais empregadas, no âmbito da concertação, para promover aproximação política no campo do agronegócio, cabe destacar, neste trecho, o uso de um discurso que adquiria importância naquele começo dos anos 2010. De acordo com o que mostram Montero, Arruti e Pompa (2012), em sua proposta de Antropologia do Político, a mobilização de determinadas categorias pode ser operada como ferramenta para promover a convergência de atores anteriormente dispersos. Esse foi, exatamente, o caso da ideia de "insegurança jurídica” (ver CNA, 2008; Abag, 2010, p. 31), que passou a ser utilizada reiteradamente para identificar, em uma narrativa mais inteligível, na perspectiva de líderes do campo, ameaças ao avanço de sua apropriação de terras no país. Ao promover a percepção do que seriam as adversidades políticas mais importantes para esses atores - primeiramente, quanto ao tema ambiental; em seguida, ao indígena; e, por fim, em relação a outras questóes -, o agenciamento do termo facilitou a aproximação de representações da agropecuária e das indústrias a montante e jusante (Pompeia, 2018). Além disso, a versão positivada da categoria, "segurança jurídica", auxiliou-os a organizar suas agendas com pleitos direcionados às questôes amplas - como a ambiental, a indígena e a quilombola.

Procurando aprofundar as "agroestratégias" - termo que Almeida emprega para tratar de operaçóes coordenadas entre agentes do agronegócio para enfraquecer os instrumentos de proteçáo aos direitos territoriais das minorias rurais e intensificar processos de desterritorialização (Almeida, 2010) -, núcleos da concertação passaram, ademais, a intensificar a promoção conjunta de um aparato de justificação para questionar as lógicas inerentes às questóes amplas, particularmente aquelas relativas à terra. Não fortuitamente, a ênfase para mudar a imagem do "agronegócio" constava da carta política redigida pela Fiesp e pela Abag, em 2010 (ver Abag, 2010). Tratava-se, nas palavras de Almeida, de engendrar uma "visão triunfalista dos agronegócios" (Almeida, 2010, p. 110).

Próprias de regimes de justiça, as justificaçôes estão envoltas em contextos nos quais atores em disputa se veem provocados, diante de críticas, a fundamentar suas posiçóes. Para argumentar com eficácia, eles precisam remeter seus discursos a determinadas regras comuns de aceitabilidade, que seriam lógicas de justificação (Boltanski \& Chiapello, 2005; Boltanski \& Thévenot, 2006). ${ }^{8}$ Desse pressuposto das distintas lógicas resulta que um dos principais embates nesses regimes consiste em estabelecer qual delas é a mais legítima para ser utilizada em cada controvérsia - conceito que Montero emprega para aludir a debates que acabam por instituir um problema social, a ser tratado de maneira pública (Montero, 2012).

Em controvérsias ligadas a questôes como a agrária, a ambiental e a indígena, agentes da concertação 
respondem a críticas procurando desestabilizar e substituir as lógicas de justificação sobre as quais se ancoram os atores que os contestam. Com efeito, no lugar de debates assentados em valores como distribuição, sustentabilidade e direitos, eles procuram forçar a proeminência de lógicas macroeconômicas, mobilizando reiteradamente, para tanto, em arenas dominantes da esfera pública (Fraser, 1997), estatísticas como aquelas que enfatizam a importância do "agronegócio" no Produto Interno Bruto (PIB) e nos empregos do país. ${ }^{9}$

Entretanto, é importante enfatizar que essa tecnologia estatística é operada por meio de sinédoques políticas, como indicado anteriormente. Enquanto o "peso" do agronegócio na economia é medido com base na noção de agribusiness, os dividendos dessa mobilização são auferidos, substancialmente, por núcleos da concertação, os quais, considerados conjuntamente em sua representatividade política, não conseguem abranger o amplo perímetro de funçóes previstas na noção. Se, como categoria, o agronegócio é "tudo", conforme anuncia a campanha veiculada pela Rede Globo, sua dimensão política - a concertação - é somente parte dele. A despeito das sinédoques, as estatísticas macroeconômicas têm sido, ao lado de ideias-força como promoção de segurança alimentar, elemento fundamental a contribuir para o aumento da capacidade de tradução de pleitos dessas nucleações em açóes do Estado (Pompeia, 2018).

O êxito das agroestratégias é exemplar do referido poder. No governo de Dilma Rousseff (Partido dos Trabalhadores, 2011-2016), coetâneo à criação e à consolidação do IPA, as demarcações de TIs foram praticamente paralisadas (Pompeia, 2018) ${ }^{10}$. Nas gestóes de Michel Temer (Movimento Democrático Brasileiro, 2016-2018) e, principalmente, de Jair Bolsonaro (sem partido ${ }^{11}$, 2019-), nucleaçóes dominantes da concertação, inserindo-se de modo central no processo político nacional, passaram a direcionar sua ação no tema indígena no sentido de legitimar o uso de áreas de TIs demarcadas para a produção de commodities agropecuárias.

Contudo, as movimentaçóes políticas que contribuíram decisivamente para o incremento da influência de líderes da concertação em relação ao Estado foram bastante tortuosas. Durante a primeira metade dos anos 2010, o IPA continuaria a se fortalecer, atraindo mais entidades para sua órbita e estabelecendo-se, paulatinamente, em articulação institucionalizada com a FPA, como o principal núcleo de representação no campo do agronegócio. Em consequência, tal fato implicou a reorganização de outras nucleaçôes importantes nesse domínio, como a CNA.

Se as relações entre essa Confederação e as entidades agrupadas no IPA foram mais congruentes durante os embates acerca do Código Florestal, elas seriam substantivamente alteradas nos anos que se seguiram a tais confrontos legislativos. Para essa modificação, a transição de Kátia Abreu em direção ao Mapa mostrou-se essencial (Pompeia, 2018).

Com o objetivo de respaldar o segundo mandato de Dilma Rousseff, crescentemente antagonizado por núcleos da concertação, a então ministra fez uso de sua autoridade sobre a CNA - como presidente licenciada - para tentar administrar os protestos de agentes patronais em relação ao governo federal. Paralelamente, procurando disputar a liderança da representação no campo do agronegócio, Abreu decidiu criar um órgão composto por representações da agricultura patronal e indústrias, o Fórum das Entidades Representativas do Agronegócio (FERAB) (Sociedade Nacional de Agricultura, 2015).

No entanto, a contrariedade dos demais agentes da concertação com o Executivo prevaleceu. Depois de um breve período de medição de forças com o IPA, o FERAB retrocedeu, enquanto o governo Dilma caminhava para seu fim. Nessas disputas, um grupo de entidades afastou-se da órbita da CNA e inseriu-se no Instituto, tornando-o ainda mais relevante para tratar de questôes transversais - como a ambiental e a indígena - e, em contrapartida, deixando menos influente a Confederação. ${ }^{12}$

A gestão que, em seguida, assumiu essa organização sindical de âmbito nacional buscaria a reaproximação com a FPA, ao mesmo tempo em que criaria o Conselho do Agro, nele envolvendo as principais representaçôes da agricultura patronal (ver CNA, 2018). Era uma tentativa de recuperação de poder diante do destaque do IPA. A partir de então, para serem eficazes em temas políticos amplos, representaçóes do campo do 
agronegócio precisariam ter capacidade de agregar, de modo organizado, grande número de atores.

Tal movimento de tendência centrípeta, fortalecendo o terceiro padrão de representatividade nesse campo, afetou de modo marcante as relaçóes dos agentes privados com os Poderes Legislativo e Executivo. No que se refere ao Parlamento, a consolidação do IPA, atribuindo caráter sistemático e institucionalizado às negociaçôes entre empresários e políticos, foi a pedra angular para ampliar a coesão da FPA. Simultaneamente, o progressivo concerto entre IPA, FPA e CNA funcionaria, a despeito de alguns desencontros, para aprofundar o pacto de economia política dos núcleos do agronegócio com o governo federal.

Considerando a reconfiguração política no campo do agronegócio nos anos 2010 como fator fundamental para o aumento de poder de agentes da concertaçáo, cabe em seguida examinar, de modo sistemático - e com fundamento em trabalho de campo -, seu modus operandi. Em outras palavras, cumpre estudar quais os problemas mais relevantes para os atores heterogêneos atuarem em concerto e quais os dispositivos instituídos por eles para lidar com tais adversidades. Inicia-se pelo exame das dificuldades.

\section{Conflitos internos no campo do agronegócio: ameaças à concertação política}

Se não eram raras as divergências entre representaçóes patronais no contexto de fragmentação que se seguiu à industrialização da agricultura (Graziano da Silva, 1991; 2010; Mendonça, 2008; Bruno, 2017), há, atualmente, no que se identifica como terceiro padrão de representação política no campo do agronegócio, discordâncias nos três níveis da concertação. Tais problemas têm potencial, dentre outros desdobramentos, para afetar negativamente sua coordenação, minorando a capacidade de tradução de seus agentes.

Dentre os conflitos, podem-se destacar os que ocorrem entre as entidades - internamente aos núcleos políticos intersetoriais -, como também aqueles que se manifestam nas relações entre essas nucleaçóes ampliadas, e os que abrangem as interaçóes dos agentes empresariais com o governo federal. Os embates nos referidos núcleos acontecem tanto entre representaçóes de um mesmo setor, quanto entre setores. No primeiro caso, trata-se, na maior parte, de atritos pela centralidade na condução de seus procedimentos internos. Um exemplo foi a competição entre representaçôes do algodão e da soja pela liderança do IPA na metade dos anos 2010 (Tavares, 2018). ${ }^{13}$ Os desacordos são igualmente relevantes entre as indústrias. Os casos mais marcantes são os desentendimentos relacionados a habilitaçóes para exportar entre a Associação Brasileira das Indústrias Exportadoras de Carnes (Abiec), liderada pela JBS, e a Associação Brasileira de Frigoríficos (Abrafrigo), que representa médios frigoríficos, além da Marfrig.

As rivalidades intersetoriais são mais frequentes do que as intrassetoriais. Nesse sentido, o executivo de uma instituição da agropecuária patronal admite que, embora existam incentivos à cooperação entre setores dentro dos CAIs, "[...] há momentos em que essa relação não é tão amistosa assim” (Associação 1, entrevista, 16 fev. 2019). Nas interaçóes entre a agropecuária e indústrias, as disputas distributivas são um dos aspectos mais salientes (Graziano da Silva, 1991). No que se refere a tais embates, um caso frequentemente relatado pelas poucas entidades que se dispóem a tratar do tema é aquele entre representações dos pecuaristas e dos frigoríficos, cabendo destaque, ainda, para as relaçóes entre sojicultores e tradings, e entre representaçóes da agricultura patronal e corporações de agrotóxicos. Não é casual, portanto, que a entrada de entidades industriais sofra resistência nos fóruns dominantes do agronegócio.

A seguir, remetemos aos conflitos entre as nucleaçóes ampliadas, nas quais a rivalidade central ocorre entre o IPA (na retaguarda da FPA) e a CNA. Nesse caso, há mais uma concorrência pela liderança da representação do vasto, amplo e heterogêneo conjunto de atores privados da concertação do que diferenças quanto ao posicionamento político. A Confederação e a FPA têm, a propósito, um histórico de competição (ver Tavares, 2018), que inclui projetos pessoais de seus líderes, acusaçóes de contrabando de informaçóes estratégicas e casos de cooptação de membros - dentre eles a contratação, em 2019, pela Confederação, do ex-presidente da FPA, Nilson 
Leitão. Tal medição de forças prejudica as estratégias de convergência: por um lado, dificultando algumas iniciativas legislativas - como no caso relacionado à proteçáo de cultivares -, e, por outro lado, gerando sombreamento de funçóes.

Para além do IPA e da CNA, cabe mencionar outros agentes que têm obtido crescente incidência no campo do agronegócio e, por vezes, antagonizado as decisões políticas dessas nucleações dominantes. Em 2019, a proximidade - pessoal e política - entre o presidente Jair Bolsonaro e Luiz Antônio Nabhan Garcia garantiu inédito destaque a esse líder da UDR, atribuindo influência para uma entidade de representação monossetorial que há muito se havia enfraquecido no âmbito do agronegócio. $\mathrm{Na}$ agenda ambiental, especificamente, deve-se ressaltar que a Coalizão Brasil Clima, Florestas e Agricultura (Coalizão) tem apresentado posicionamentos progressistas em defesa do meio ambiente, com propostas e justificaçóes contrárias àquelas avançadas pela maioria dos núcleos da concertação política do agronegócio.

Por fim, outra dimensão de atritos envolve as relaçóes entre os agentes privados e determinados atores do Estado. Inicia-se pela análise relativa ao Poder Legislativo. As divergências entre as nucleaçôes do campo do agronegócio traduzem-se, em determinadas ocasiões, em divisóes no âmago da FPA, o que enfraquece a tradução da agenda dos atores privados em agenda parlamentar. $\mathrm{O}$ trabalho de campo permitiu constatar, ademais, a existência de deputados e senadores que atuam concertados com o IPA e, paralelamente, a ação de parlamentares que operam de maneira mais independente do Instituto. Aliás, a dificuldade de coordenaçáo entre atores políticos desses dois grupos da bancada é um dos fatores de maior relevo a intensificar discordâncias sobre a questão ambiental no campo do agronegócio.

Durante a pesquisa no Congresso Nacional, foi possível identificar, ainda, diferenças relevantes entre a Câmara dos Deputados e o Senado Federal no que diz respeito a tramitaçóes vinculadas diretamente a interesses de líderes da concertação. Sobretudo os deputados estão sistematicamente próximos ao IPA, ao passo que é mais frágil a participação de senadores. Esse descompasso resulta em problemas nas votaçóes, como no caso da tentativa de alteração do Código Florestal em 2019 (ver Brasil, 2018).
Enquanto, no Poder Executivo Federal, o Mapa - e, mais recentemente, o Ministério do Meio Ambiente (MMA), embora de maneira não tão bem coordenada ${ }^{14}$ - tem operado sob influência de líderes da concertação, há, em contrapartida, ministérios estratégicos com os quais tais lideranças se indispóem frequentemente. O receituário neoliberal do Ministro da Economia, Paulo Guedes, por exemplo, confronta-se com os constantes apelos pela manutenção de isençôes tributárias e por maior aporte de recursos públicos. Por sua vez, a atuação do Ministério das Relações Exteriores, com as críticas políticas à China e com a aproximação a Israel, dentre outras açóes, é vista, no campo do agronegócio, como potencial geradora de problemas para a venda de commodities aos chineses e aos países árabes, notáveis parceiros comerciais da inserção primário-exportadora do Brasil.

$\mathrm{Na}$ administração desses problemas, os agentes $\mathrm{da}$ concertação mobilizam uma série de expedientes, que são o tema da próxima (e última) parte deste artigo.

\section{Dispositivos de racionalizaçáo do tratamento das relaçóes: promoçáo da convergência política}

Consideradas as inúmeras divergências nas relaçóes entre os agentes do campo do agronegócio, as estratégias de concertação somente podem funcionar de forma exitosa por meio da mobilização de dispositivos de aproximação política, administração de conflitos e negociação de acordos. Dentre os mais relevantes, serão analisados: (1) o agenciamento da categoria agronegócio; (2) a ênfase em temas políticos amplos; (3) o protocolo de administração de conflitos nos bastidores; e (4) o estabelecimento de hierarquias e divisão de funções.

\section{A categoria agronegócio}

Criada na década de 1950, nos Estados Unidos, por demanda das indústrias de alimentação, que precisavam aprofundar o entendimento de suas relaçôes com a agropecuária, a noção de agribusiness procurava romper com perspectivas compartimentadas de estudo do mundo rural. Ao lado do lançamento de 
metodologia contábil para esse novo objeto de análise - a definição original de agribusiness era "[...] a soma total de todas as operaçôes envolvidas na produção e distribuição de alimentos e fibras" (Davis, 1955, p. 5$)^{15}$-, a ênfase intersetorial sobressaía-se dentre as principais características da noção.

No Brasil, o termo seria incorporado em pesquisas a partir de desdobramentos da industrialização da agricultura (Kageyama et al., 1990). Assim, foi com o intuito de melhor compreender a constituição de cadeias produtivas que o referido termo passou a ser usado (Passos Guimarães, 1975). Embora a ideia de aproximaçóes intersetoriais relacionadas à agropecuária tenha sido apreendida (e nomeada) de várias formas a partir dos anos 1970 (Belik, 2007; Ramos, 2007), e também influenciada por autores franceses - a exemplo de Malassis (1975) -, CAI foi a expressão que adquiriu maior relevo para defini-la, seja em sua forma agregada (Muller, 1989), seja na desagregada (Kageyama et al., 1990).

Com a deterioração da política de crédito rural subsidiado, os agentes patronais que procuraram revertê-la tomaram a decisão de recuperar o termo original de Davis e Goldberg para fundamentar um projeto político-econômico de agribusiness no país (Bittencourt de Araújo; Wedekin; Pinazza, 1990). Dentre outras razóes, eles entendiam que, enquanto essa categoria norte-americana trazia uma série de incentivos para as aproximaçôes intersetoriais, assumindo-as como complementares e não conflitivas, as formulaçôes com base na noção de CAI(s) abordavam-nas, em contrapartida, de forma crítica (Pompeia, 2018).

Ao longo dos anos 1990 e 2000, uma materializaçáo essencial do referido projeto consistiu em complexo processo de tradução da perspectiva de agribusiness/ agronegócio em coletivos políticos intersetoriais, exatamente no sentido descrito por Montero, Arruti e Pompa, quando enfatizam a importância da historicização de categorias em seu modelo antropológico de constituição e atuação de coletivos políticos (Montero, Arruti e Pompa, 2012). Com fundamento na noção de agronegócio - e também em reação ao agenciamento político da categoria -, núcleos apresentando preponderância das indústrias - como a Abag - e da agricultura patronal - a exemplo do Conselho Superior de Agricultura e Pecuária do
Brasil (Rural Brasil) - foram formados durante quase duas décadas, em longo movimento de tentativas e erros, embates e aproximaçōes, entre representaçóes dos setores primário e secundário. Tais experiências práticas foram basilares para que, nos anos 2010, a atuação intersetorial pudesse ser consolidada no campo do agronegócio. Essa consolidação constitui, por sua vez, referência central para a proeminência do terceiro padrão de organização e representatividade nesse campo, conforme se argumenta no início do trabalho.

A fim de embasar a afirmação sobre o estabelecimento da intersetorialidade como forma dominante de ação patronal no campo do agronegócio, apresentam-se, a seguir, elementos que a corroboram, com indicaçóes das composiçóes relativas atuais de seus principais núcleos. Para realizar as quantificaçóes, adotou-se divisão setorial entre entidades da "agropecuária" e das "indústrias". Cabe ressaltar que a separação é aproximativa, pois há casos tanto daquelas com atuação destacada no setor primário que também acumulam funçóes secundárias (sendo o principal exemplo a Organização das Cooperativas Brasileiras), quanto de associaçóes industriais cujos integrantes atuam, verticalmente, na agricultura (como a UNICA).

Salienta-se que, dado o foco da segmentação proposta - privilegiando a comparação, internamente a cada núcleo, entre entidades dos dois setores politicamente mais relevantes no domínio da concertação -, foram consideradas nos cálculos as associaçôes nacionais, regionais e estaduais da "agropecuária" e das "indústrias", e desconsideradas empresas e organizaçôes de segmentos terciários. Os dados foram obtidos entre março e maio de 2019.

O IPA tem destacada participação das "indústrias", que somam 26 entidades $(60,5 \%$ do total), diante de 17 da "agropecuária" (39,5\%) (elaboração própria com base em IPA, 2019). A sólida presença do setor secundário no Instituto foi essencial para sua eficácia na relação com o Estado e para a centralidade que adquiriu na concertação. Com essa composição, em que há relevante participação tanto do setor primário quanto do secundário, “[...] a representatividade fica maior", como enfatiza o dirigente de uma organização por produto (Associação 2, entrevista, 13 fev. 2019). Já o presidente de uma entidade da agricultura 
patronal afirma que a influência no Parlamento seria bem menos efetiva se não houvesse no IPA essa face intersetorial: "Não podemos levar para o Congresso propostas de legislação que tenham impacto no agronegócio sem ouvir a todos" (Associação 3, entrevista, 04 abr. 2019). ${ }^{16}$

Diante do crescimento da representatividade do IPA, outros líderes do agronegócio foram forçados a reagir na direção da intersetorialidade. Em 2015, quando criou o FERAB no âmbito das disputas por influência no campo, Kátia Abreu precisou incluir no fórum, além das representaçôes da agricultura patronal, aquelas do setor secundário. Do total de entidades oficialmente participantes no FERAB, 10 (58,8\%) eram da "agropecuária”, enquanto 7 (41,2\%) vinculavam-se às "indústrias" (elaboração própria com base em Sociedade Nacional de Agricultura, 2015).

No planejamento inicial do Conselho do Agro constava, segundo alguns dos entrevistados, a decisão de abranger somente representaçôes do setor primário. Contudo, a presença do setor secundário náo tardou a se impor: no ano seguinte à fundação desse Conselho, a Abag passou a compô-lo oficialmente; nas eleiçóes de 2018, a Fiesp e a UNICA associaram-se a ele para escrever a carta de pleitos mais influente da concertação: "Futuro é Agro" (CNA, 2018); no início de 2019, a UNICA integrou-se oficialmente ao fórum. Embora a predominância no Conselho do Agro seja, indubitavelmente, da "agropecuária", com 14 entidades (87,5\%), as "indústrias" têm conquistado espaço, participando com 2 associações (12,5\%) em sua composição relativa (elaboração própria com base em CNA, 2019).

Apresentando atuação mais independente no campo do agronegócio, ou seja, menos ligada aos pleitos dos agentes dominantes da concertação - como as duplas FPA/IPA e CNA/Conselho do Agro -, a Coalizão também se caracteriza pela composição intersetorial. Há nela nove associações das "indústrias" (75\%) e três da "agropecuária" (25\%) (elaboração própria com base em Coalizão, 2019). ${ }^{17}$

A Abag continua, em 2019, a ser uma organização com preponderante participação do setor secundário. Ao se analisarem entidades a ela associadas, verifica-se a presença de nove $(81,8 \%)$ das "indústrias", ante duas $(18,2 \%)$ da "agropecuária” (elaboração própria com base em Abag, 2019).

Cumpre apontar ainda um segundo desdobramento relevante do agenciamento da categoria agribusiness: sua utilização, por núcleos da concertação, para a construção do aparato de justificação no país. Com a mobilização de estatísticas amparadas na visão agregada e intersetorial da categoria, pôde ser defendida a proposição de que, tomado em conjunto, o "agronegócio" seria - ao contrário da agropecuária em si - extremamente relevante para a economia nacional (Pompeia, 2018).

No entanto, conforme mostrado anteriormente, os agenciamentos de quantificaçóes macroeconômicas frequentemente são operaçôes de sinédoque política, uma vez que o "tamanho" do agronegócio no PIB e nos empregos é medido com fundamento na noção de agribusiness, ao passo que os dividendos dessa mobilização são apropriados, em importante medida, por líderes da concertação, a qual, como manifestação política, inexiste com tal perímetro de funçóes previstas na noção. Enquanto o agronegócio como conceito é totalizador, sua dimensão política é consideravelmente menos abrangente (Pompeia, 2020).

\section{Temas amplos}

Ao conseguirem diminuir a relevância atribuída à questão agrária nas agendas pública e estatal durante os anos 2000, atores do campo do agronegócio tinham passado a focar as demais grandes questóes relacionadas diretamente à terra - afora outras, como a trabalhista e a alimentar. $\mathrm{Na}$ referida década, a fragmentação política entre organizaçóes - característica tipificada por Graziano da Silva em referência a um segundo padrão de representatividade nesse campo - implicava ineficácia relevante para a ação política com tais temas amplos.

Um passo essencial para superar essa dificuldade foi dar maior inteligibilidade às referidas questóes. Para isso, foi significativo o agenciamento de algumas categorias, como (in)segurança jurídica, que passara a ser utilizada para ajudar a unificar, em uma narrativa mais evidente para atores do campo do agronegócio, o que seriam as grandes ameaças ao aprofundamento de suas agroestratégias. Auxiliada por palavras como a 
citada, a percepção de preocupações compartilhadas entre os distintos agentes desse campo serviu como aglutinadora entre eles, dando novo impulso aos trabalhos para construção de organizaçóes intersetoriais abrangentes inspiradas na ideia de agronegócio. Ao mesmo tempo em que criavam artifícios para facilitar a união em função de temas amplos, os agentes em concerto também fortaleciam, motivados sobretudo pela corrida por terras (Sauer; Borras Jr., 2016), justificações baseadas em sinédoques políticas, que eram operadas para a desestabilizaçáo das mais variadas lógicas críticas à sua atuação, conforme se argumentou anteriormente.

Com o acirramento dos embates sobre o Código Florestal, ficou ainda mais evidente, para líderes da agricultura patronal e das indústrias, que a ação dispersa e frequentemente defensiva não resultaria nos objetivos esperados em relaçáo às questões transversais. Decidiu-se, então, consolidar um núcleo que já vinha sendo fomentado, mas permanecia circunscrito a poucas entidades da agropecuária patronal: o IPA. Por meio dele, a ação política de agentes do agronegócio sobre a questão ambiental começaria a obter mais resultados. Por um lado, porque com o Instituto se avançou na construção de consensos entre os atores heterogêneos do campo do agronegócio, permitindo a agregação de representatividade; por outro, porque com ele se reestruturaram as conexóes público-privadas nesse campo, fortalecendo a FPA.

Tão importante quanto essas duas ordens de mudanças foi a racionalização de tratamento dos temas amplos que o IPA fomentou no campo do agronegócio com sua consolidação. Conforme foi possível observar durante o trabalho de campo, suas comissóes, especializadas nas questôes transversais, passaram a operar para: (1) facilitar consensos entre as entidades sobre cada um dos assuntos politicamente abrangentes; (2) acrescentar conhecimento técnico e justificatório ao desenvolvimento dos pleitos baseados nesses acordos; e (3) promover tais reivindicaçóes, com auxílio de parlamentares, nos Poderes Legislativo e Executivo.

Essa forma de ação política especializada em temas políticos ampliados - traço essencial do terceiro padrão de representatividade no campo do agronegócio, ao lado da proeminência de organizaçóes intersetoriais e abrangentes - influenciou as demais associaçóes desse campo, como, por exemplo, a CNA, que organiza os debates no Conselho do Agro com a mesma proposta de foco em temas transversais e evitação de assuntos específicos de cada cadeia produtiva. Nas relaçóes entre os núcleos dominantes, também se nota a aglutinação de forças para a promoção de metas extensivas comuns, como impedir o reconhecimento de territórios tradicionalmente ocupados e atuar sobre a questão ambiental. Mais recentemente, as relaçóes da FPA com a Presidência da República têm sido igualmente inspiradas em macrotemas - embora, nesse caso, ainda de maneira incipiente.

\section{Bastidores e esfera pública}

Outro dispositivo indispensável no âmbito da concertaçâo consiste no uso dos espaços de convergência para (1) administrar conflitos a portas fechadas - tanto dentro dos núcleos, quanto entre as próprias nucleações - e (2) produzir consensos possíveis de serem encenados para ampliar a capacidade de tradução conceituada por Fraser (2014). A regra tácita consiste em não emitir, para a opinião pública e para o Poder Executivo, sinais de diferenças entre agentes do agronegócio, seja por meio de ambiguidades discursivas, de pleitos contrastantes ou, até mesmo, da revelação de disputas internas por influência.

Como enfatizou Goffman, por meio de análise sociológica baseada em perspectiva teatral, é nos bastidores que se pode exercer maior controle sobre o que será mantido em segredo e o que será apresentado ao público (Goffman, 1956) - um procedimento que garante filtro político fundamental para os agentes em concerto. Segundo declarou ao autor um deputado do núcleo da frente do agronegócio a respeito do tratamento dos conflitos na engrenagem IPA/FPA, a "[...] divergência, você deixa ela quieta, calada" (Parlamentar 1, entrevista, 03 jul. 2019). ${ }^{18}$

O IPA e o Conselho do Agro têm esse caráter de bastidores. O Instituto se esforça para não aparecer: não tem site, suas reunióes são dificilmente acessíveis e seus líderes raras vezes se manifestam publicamente enquanto membros dele. Por sua vez, o Conselho concebido pela CNA é ambiente pouco poroso, até mesmo para organizaçóes do campo do agronegócio 
que não o integram de modo oficial. No caso específico da dupla IPA/FPA, o protocolo de portas fechadas serve tanto para entidades que náo querem aparecer defendendo determinados pleitos, quanto para parlamentares em busca de notabilidade. As associaçóes organizam-se nos bastidores, decidindo agendas e criando, com auxílio técnico, subsídios jurídicos para implementá-las e justificaçôes para legitimá-las; os políticos recebem-nas em espaço privado, avaliam sua oportunidade e defendem-nas no Congresso ${ }^{19}$.

Com o Poder Executivo, negociaçóes a portas fechadas também são fundamentais. Nesse sentido, destaca-se a tradicional incidência de líderes da FPA e da CNA sobre o Mapa. Com outros ministérios e a Presidência da República, também ocorre o diálogo de bastidores, mas de maneira assistemática e usualmente em situaçóes franqueadas por líderes do governo federal, sobretudo quando da proximidade de importantes votaçóes que requeiram a influência da Frente. Porém, esses canais estabelecidos com o Planalto têm mostrado eficácia relativa: mesmo funcionando com êxito em certas circunstâncias, eles não têm evitado algumas confusóes e desentendimentos, como, por exemplo, na questáo ambiental.

\section{Hierarquias e divisão de funçōes}

O quarto e último dispositivo a ser analisado é o emprego de hierarquias e divisão de funçôes para ampliar a racionalização das relaçóes de poder e garantir maior êxito às açóes convergentes no âmbito da concertaçáo. Nas nucleaçóes dominantes do campo do agronegócio, a ascendência formal da agropecuária é elemento primordial para equilibrar as interaçóes com as indústrias, as quais têm vantagem no contexto econômico dos CAIs.

Se, no Conselho do Agro, é possível notar a presença predominante de entidades do setor primário - além da liderança da própria CNA -, no IPA, as associaçōes da "agropecuária" têm asseguradas, desde a fundação do Instituto, a presidência e a maioria das posiçóes na direção. Trata-se de fator extremamente relevante, pois cabe ao presidente do IPA, auxiliado pela direção, arbitrar o planejamento estratégico das agendas prioritárias e liderar os contatos com a cúpula da FPA.
Entretanto, enquanto as estratégias de inserção privilegiada de lideranças da agropecuária nos núcleos atribuem, de um lado, certa proeminência e força política aos segmentos primários, elas também apresentam outra face, que interessa diretamente às indústrias, pois o que tende a ser encenado e apreendido como de interesse do "produtor" constitui, ao mesmo tempo, um mecanismo de legitimaçáo que permite às corporaçóes do setor secundário, especialmente às multinacionais, avançarem suas agendas sem grande alarde. Conforme revela o presidente de uma organização nacional de indústrias a montante da agropecuária, "[...] o agricultor tem uma imagem [...] de que precisa desse apoio, de que precisa dessa reivindicação, de que é mais agredido em vários pontos do que, entre aspas, uma indústria" (Associação 4, entrevista, 23 abr. 2019).

Além disso, é importante chamar atenção para a divisão de funçôes entre as distintas entidades dentro do IPA, que acontece por meio de suas comissóes - das quais se tratou anteriormente -, ordenadas por temas amplos. Nelas, os atores empresariais se agrupam em torno de assuntos transversais que mais lhes interessam, em interação organizada com um parlamentar também concentrado na mesma questão.

No que concerne às relaçôes entre núcleos, as hierarquias e divisóes de funçôes são parte essencial da intensificação da convergência e do aumento da eficácia de suas açóes políticas pactuadas. A dupla FPA/IPA é dominante nesse campo, tendo sua atuação basilar no Parlamento - embora também tenha notável capacidade de influenciar a agenda do governo federal.

Já a CNA e seu Conselho do Agro figuram em segundo lugar, com foco nas relaçóes com o Executivo; sua força, a propósito, advém de dois elementos preponderantes: (1) o fato de a Confederação ser o órgão máximo de representação oficial da agricultura patronal - frequentemente entendido pelo Estado como o principal agente a ser ouvido sobre esse segmento; e (2) a capacidade de seu Conselho em reunir entidades representantes das principais commodities agropecuárias. Como destacado antes, foi a CNA que, acompanhada de seu fórum de entidades, da Fiesp e da UNICA, liderou a elaboração do documento de propostas com maior influência na campanha presidencial de 2018 (ver CNA, 2018). 
Apesar das competiçóes e desencontros entre os dois agentes dominantes na concertação - IPA/FPA e CNA/Conselho do Agro -, ambos têm ampliado sua convergência, somando forças para agir em temas estratégicos, como os relacionados à política agrícola, à tributação, aos povos indígenas e ao meio ambiente, para citar alguns dos principais. Ademais, dada sua capacidade técnica - citada por muitos entrevistados -, a CNA frequentemente constrói relatórios para que pleitos transversais da concertação sejam justificados no Congresso e na imprensa, o que contribui de modo importante para a ampliação da capacidade de tradução de seus atores políticos.

Por outro lado, como observado no trabalho de campo, os encaminhamentos legislativos decididos em seu Conselho do Agro precisam da FPA, pois a força dessa Frente assegura bastante agilidade e influência nas tramitações no Congresso Nacional. Vale destacar, nessa direção, que sua articulação - por vezes, conflituosa - com o IPA garante que a ação não ocorra por intermediação parlamentar fragmentada, de deputado em deputado, mas sim por meio de bloco político. Foi por essa razão, a propósito, que a Confederação recentemente se associou, de modo formal, ao Instituto, em mais uma demonstração da consolidação do terceiro padrão de representatividade no campo do agronegócio.

A Abag continua participando ativamente em diversos âmbitos da concertação, embora de forma distante do objetivo maior de seu fundador, Ney Bittencourt de Araújo, para quem a entidade deveria liderar a representação política do agronegócio (Abag, 1993). O caráter de multiafiliação no campo, identificado por Graziano da Silva $(1991$; 2010) e Bruno (2015) - ou seja, a inserção de suas entidades em uma ampla gama de fóruns -, faz bastante sentido para a Abag: essa Associação financia o IPA, é membro oficial do Conselho do Agro, tem liderança na Coalizão e participação no Cosag. Entretanto, ela é entendida como uma entidade a mais por alguns dos entrevistados, ou como representação das indústrias, por outros. Para essa perda de influência, contribuíram conflitos - ocorridos nos anos 1990 e 2000 - relacionados à liderança das açóes do campo agronegócio, bem como o fato de a Abag ter se estabelecido antes como um agrupamento de empresas do que de entidades (Pompeia, 2018).
Após destaque na segunda metade dos anos 2000, o Cosag/Fiesp tem perdido relevância no campo do agronegócio, ${ }^{20}$ embora a força das indústrias sediadas em São Paulo ainda lhe garanta certo prestígio. Reconhecendo a diminuição de sua centralidade, essa representação associou-se, recentemente, ao IPA, e aproximou-se da CNA. Porém, enquanto a Abag é apontada como bastante dinâmica, o Cosag é visto como menos efetivo, por constituir-se, acima de tudo, como fórum de debates, e não de ação política direta-conforme indica o diretor executivo de entidade de indústrias a montante da agropecuária (Associação 5 , entrevista, 25 fev. 2019). Há, ainda, aqueles que ressaltam seu caráter mais circunscrito a São Paulo (Associação 3, entrevista, 04 abr. 2019), enquanto outros, como o presidente de uma representação da agricultura patronal (Associação 6, entrevista, 02 abr. 2019), apontam que sua atuação é orientada com maior ênfase para a produção sucroalcooleira - efetivamente, a área de seu atual presidente, que trabalha para a francesa Tereos.

Com novo ímpeto, a UDR quase chegou, por meio de seu líder, Nabhan Garcia, a estar à frente do Mapa em 2019. Ao tomarem conhecimento de tal possibilidade, as entidades presentes no IPA e a direção da FPA agiram para evitá-la, indicando para assumir o posto a então presidente da Frente, deputada Tereza Cristina (Democratas, Mato Grosso do Sul). Ao mesmo tempo, esses agentes inseriram a UDR subalternamente no referido ministério, nos temas fundiários sobre os quais essa organização coincide politicamente com os núcleos dominantes da concertação.

De sua parte, a Coalizão tem funcionado - conforme indicado anteriormente - como órgão relativamente autônomo em relação aos núcleos preponderantes na concertação política do agronegócio. Embora alguns de seus associados integrem tais nucleaçōes, sua ênfase em pauta de atuação definida nas questóes ambiental e climática, com marcante participação de ambientalistas, traduz-se em posiçóes que, por vezes, opóem-se àquelas da FPA e da CNA. No entanto, a presença de entidades do agronegócio no fórum opera para dificultar sua atuação mais incisiva em algumas agendas, como a de defesa das TIs.

No que se refere ao Estado, devem-se citar as hierarquias dentro da bancada, que é liderada por 
aproximadamente dez membros de sua mesa diretora. Além disso, há as divisóes dos parlamentares entre (1) as comissóes do IPA e (2) as comissóes da Câmara dos Deputados (Vigna, 2001; Bruno, 2015), neste espaço hegemonizando a de Agricultura, Pecuária, Abastecimento e Desenvolvimento Rural, e inserindo seus principais quadros em outras comissóes altamente importantes para líderes da concertaçáo, como a de Constituição e Justiça e de Cidadania, e a de Finanças e Tributação. Na estrutura do Poder Executivo, o Mapa e, de certa forma, o MMA, funcionam, conforme apontado antes, como órgãos estatais sob influência dos agentes concertados nos temas, respectivamente, da agropecuária e do meio ambiente, permanecendo, entretanto, maior dificuldade de coordenaçáo com outras pastas.

\section{Consideraçóes finais}

O presente artigo identificou e examinou um novo padrão de organizaçáo e representação no campo do agronegócio, consolidado nos anos 2010 para incidir sobre questóes políticas amplas, notadamente aquelas vinculadas a temas fundiários, como a ambiental e a indígena. Para definir essa modalidade de ação política e estruturar a análise sobre ela, utilizou-se o conceito de concertação política do agronegócio, que remete a uma configuração público-privada de estratégias de convergência as quais, operadas em diversos níveis, apresentam como traços a intersetorialidade, a multilateralidade, a institucionalização, e a sistematicidade.

Com fundamento em pesquisa de campo realizada em Brasília, demonstrou-se que, para administrar conflitos e competições entre si em contexto de aceleração da corrida por terras no Brasil, os agentes em concertação empregam - preferencialmente, nos bastidores - dispositivos de orquestração de interesses, dos quais se podem destacar a ênfase em questóes transversais, o agenciamento de categorias agregadoras, e o estabelecimento de hierarquia e divisões de tarefas. Por meio da maior racionalização de suas relações, tais atores procuram aglutinar forças para ampliar sua influência sobre o Estado e, consequentemente, aprofundar seu controle sobre territórios no país.
Nesse sentido, mostrou-se que a mobilização de um aparato de justificação por esses agentes é instrumental. Contrapondo o limitado perímetro político dos núcleos concertados ao abrangente conjunto de funções agroalimentares abarcadas na categoria agronegócio, apontaram-se sinédoques políticas (confusóes entre partes e totalidades) na faceta macroeconômica do referido aparato. Apesar de essas nucleaçóes não abrangerem várias das funçóes levadas em consideração - com base na categoria - para calcular números sobre o PIB e os empregos do agronegócio, seus líderes agem como se o fizessem, tentando assim superestimar sua representatividade perante a opinião pública e o Estado.

Tratando, pois, do agronegócio como fenômeno político, o artigo procurou contribuir com a literatura de referência, no estudo sobre seu poder, ao identificar, historicizar e analisar sistematicamente sua estrutura de ação concertada.

\section{Agradecimentos}

A pesquisa foi financiada pela Fapesp (processo 2018/17886-5). Sou grato a Manuela Carneiro da Cunha, José Maurício Arruti, Guilherme Delgado, Paulo Moruzzi, Eduardo Moyano, Sergio Pereira Leite, José Graziano da Silva e Marcello Baird, além dos/as pareceristas, pelas sugestóes e comentários a diferentes aspectos da reflexão aqui exposta. Importante ressaltar que erros e omissóes são de inteira responsabilidade do autor.

\section{Notas}

1 Atributo que a afasta de noções monossetoriais, como ruralismo.

2 Por meio da ideia de multilateralidade, procura-se indicar que a concertação política do agronegócio abrange interaçấo de organizaçóes de distintos CAIs. Nesse aspecto, ela diferencia-se do emprego de "concertação" por Graziano da Silva (1991), que, como exposto acima, usa o termo para aludir a orquestraçóes de interesses em CAIs específicos. A razão é simples: guarda-se coerência, em Graziano da Silva (1991), com o segundo padrão de representatividade no campo do agronegócio; e, 
no presente artigo, com o que se define como terceiro padrão.

3 Sobre as relaçóes público-privadas envolvendo o campo do agronegócio, é necessário um esclarecimento. Por um lado, há determinados agentes estatais que operam sistematicamente na concertação política aqui definida, como a FPA; por outro lado, os agentes em concertação, incluindo, pois, os públicos, atuam para disputar as agendas e definiçóes - orçamentárias e regulatórias - do Estado, nesse caso apreendido em sentido amplo.

4 A esfera pública é entendida, no texto, como uma arena de interação discursiva e disputa política com influências sobre as agendas pública e estatal (Fraser, 1997; Montero, 2012).

5 Para análise sobre a criação da noção de agribusiness, sua inserçáo no Brasil e o processo de sociogênese desdobrado de sua mobilização no país, ver Pompeia (2018).

6 Sobre as operaçóes de sinédoque política, ver Pompeia (2018; 2020).

7 Tratava-se de duas entidades por produto e multiproduto, típicas do que Graziano da Silva (1991) nomeou como segundo padrão de relaçóes público-privadas no campo do agronegócio, conforme abordado no início do presente artigo.

8 Cabe ressaltar que o presente trabalho se apropria antes do pressuposto da diferenciação entre lógicas de justificação do que dos princípios específicos com os quais os autores citados trabalham.

9 Vale sublinhar que tal estratégia funciona com menor êxito quando utilizada em relação aos embates sobre temas ambientais, que, envolvendo escalas internacionais da esfera pública, reequilibram a disparidade de poder entre os atores em disputa e forçam líderes da concertaçáo a inflexionar o "espírito" do agronegócio, nos termos da sociologia pragmática francesa. Para análise dessa inflexáo no tema ambiental, ver Pompeia (2018).

10 Mesmo atendendo a esse e a outros pleitos de núcleos da concertação, o procedimento para retirar Rousseff do poder, em 2016, contou com decisiva participação de parlamentares ligados à FPA (Pompeia, 2018).

11 Jair Bolsonaro desfiliou-se do Partido Social Liberal em novembro de 2019.

12 Essa transição poderia ser apreendida, à primeira vista, como deslocamento típico entre os dois padróes identificados por Graziano da Silva (1991), conforme apontado na Introdução do presente artigo. Contudo, em lugar de fortalecer a fragmentação, tal transição dava ímpeto à agregação política em um fórum de natureza inédita no campo do agronegócio, o IPA.

13 Embora o livro citado traga importantes informaçôes sobre a FPA, ele deve ser lido com ressalvas, dada a adesão política do autor a essa Frente.
14 Deve-se enfatizar que a maior incidência sobre o MMA tem sido de representaçóes que ainda veem o meio ambiente como problema, e não daquelas que manifestam posiçóes mais cuidadosas sobre o tema como a Coalizão.

15 Tradução do autor de excerto do texto original "[...] the sum total of all operations involved in the production and distribution of food and fiber" (Davis, 1955, p. 5).

16 O termo "todos", empregado pelo entrevistado, deve ser entendido como operação de sinédoque política, pois o IPA está muito distante de incluir a totalidade dos atores abrangidos no conceito englobante de agronegócio.

17 Deve-se ressaltar que, no final de 2019, um conflito relacionado à questão ambiental resultou na saída de influentes entidades da Coalizão e ampliou a representatividade relativa das associaçóes "industriais" nesse núcleo.

18 Embora criticada, a quebra da regra bastidores/esfera pública ocorre em alguns casos, como nas recentes açóes da Abag na imprensa confrontando a posição majoritária no IPA de tentar mudar, novamente, o Código Florestal.

19 É importante sublinhar que o lobbying não é regulamentado no país.

20 Um exemplo relevante ajuda a evidenciar essa afirmaçáo: com a criação do Conselho do Agro na CNA, algumas entidades deixaram de frequentar assiduamente esse órgão da Fiesp.

\section{BIBLIOGRAFIA}

ALMEIDA, Alfredo Wagner Berno. (2010), "Agroestratégias e desterritorialização: os direitos territoriais e étnicos na mira dos estrategistas dos agronegócios", in A. W. B. Almeida et al. Capitalismo globalizado e recursos territoriais: fronteiras da acumulação no Brasil contemporâneo. Rio de Janeiro, Lamparina: 101-143.

ASSOCIAÇÃO BRASILEIRA DO AGRONEGÓCIO. (1993), Segurança alimentar: uma abordagem de Agribusiness. São Paulo, Abag.

ASSOCIAÇÃO BRASILEIRA DO AGRONEGÓCIO. (2010), Plano de ação 2011-2014-2020 - propostas aos presidenciáveis. Brasília, DF.

ASSOCIAÇÃO BRASILEIRA DO AGRONEGÓCIO. (2019), Associados. Disponível em: <http://www. abag.com.br/>. Acesso em: 07 mar. 2019. 
BELIK, Walter. (2007), “Agroindústria e Política Agroindustrial no Brasil”, in P. Ramos (org.). Dimensóes do Agronegócio Brasileiro Politicas, Instituiçôes e Perspectivas. Brasília, NEAD, 1: 141-170.

BITTENCOURT DE ARAÚJO, Ney; WEDEKIN, Ivan; PINAZZA, Luiz. (1990), Complexo Agroindustrial - o "Agribusiness Brasileiro". São Paulo, Agroceres.

BOLTANSKI, Luc \& CHIAPELLO, Eve. (2005), The New Spirit of Capitalism. Nova York, Verso. BOLTANSKI, Luc \& THÉVENOT, Laurent. (2006), On justification: Economies of Worth. New Jersey, Princeton University Press.

BRASIL. Medida Provisória n 867, de 2018. Diário Oficial [da] República Federativa do Brasil, Brasília, DF, 27 dez. 2018.

BRUNO, Regina. (2015), Elites agrárias, patronato rural e bancada ruralista no Brasil. Rio de Janeiro, Projeto de Cooperação Técnica UFT/BRA/083/ BRA.

BRUNO, Regina. (2017), "Bancada Ruralista, Conservadorismo e Representação de Interesses no Brasil Contemporâneo", in G. Flexor; R. Maluf. (org.). Questóes agrárias, agricolas e rurais: conjunturas e politicas públicas. Rio de Janeiro, E-papers, 1: 155-168.

CARNEIRO DA CUNHA, Manuela. (2018), "Índios na Constituição". Novos estudos CEBRAP 37, 3 (set.-dez.): 429-443.

CENTRO DE ESTUDOS AVANÇADOS EM ECONOMIA APLICADA. (2017), Metodologia - PIB do Agronegócio Brasileiro: Base e Evolução. Piracicaba, Cepea/USP.

COALIZÃO BRASIL CLIMA, FLORESTAS E AGRICULTURA. (2019), Membros. Disponível em: <http://www.coalizaobr.com.br/>. Acesso em: 31 mai. 2019.

COMPSTON, Hugh. (2003), "Beyond corporatism: A configurational theory of policy concertation". European Journal of Political Research, 42: 787-809.

CONFEDERAÇÃO DA AGRICULTURA E PECUÁRIA DO BRASIL. CNA sugere alteração no Decreto 6514 ao Ministério do Meio Ambiente. (2008), Disponível em: <https://agrosoft.org. br/2008/08/29/cna-sugere-alteracao-no-decreto6514-ao-ministerio-do-meio-ambiente/>. Acesso em: 16 ago. 2019.

CONFEDERAÇÃO DA AGRICULTURA E PECUÁRIA DO BRASIL. (2018), O Futuro é Agro: 2018-2030. Brasília, DF, CNA.

CONFEDERAÇÃO DA AGRICULTURA E PECUÁRIA DO BRASIL. (2019), Quem somos. Disponível em: <http:/www.conselhodoagro. org.br>. Acesso em: 12 abr. 2019.

DAVIS, John. (1955), "Business Responsibility and the Market for Farm Products", Boston Conference on Distribution, 17 October 1955, box 1, folder 2, John H. Davis Papers, Special Collections, National Agricultural Library, Beltsville, Maryland.

DAVIS, John \& GOLDBERG, Ray. (1957), A Concept of Agribusiness. Boston, Harvard Business School Press.

DELGADO, Guilherme Costa. (2012), Do capital financeiro na agricultura à economia do agronegócio: mudanças cíclicas em meio século (1965-2012). Porto Alegre, Editora da UFRGS.

DONER, Richard. (1991), Driving a Bargain: Automobile Industrialization and Japanese Firms in Southeast Asia. Berkeley, University of California Press.

FLEXOR, Georges Gérard.; LEITE, Sergio Pereira. (2017), "Mercado de terras, commodity boom e land grabbing no Brasil", in G. Flexor; R. Maluf. (org.). Questóes agrárias, agrícolas e rurais: conjunturas e politicas públicas. Rio de Janeiro, E-papers, 1: 56-74.

FRASER, Nancy. (1997), Justice Interruptus: Critical Reflections on the "Postsocialist" Condition. New York and London, Routledge.

FRASER, Nancy et al. (2014), “Transnationalizing the Public Sphere”, in K. Nash (ed.). Transnationalizing the Public Sphere. Cambridge, Polity.

GOFFMAN, Erving. (1956), The presentation of self in everyday life. Edinburgh, University of Edinburgh.

GRAZIANO DA SILVA, José. (1991), "Complexos agroindustriais e outros complexos". Reforma Agrária. Campinas, 21, 3, set-dez: 5-34. 
GRAZIANO DA SILVA, José. (2010), “Os desafios das agriculturas brasileiras”, in J. G. Gasques; J. E. R Vieira Filho; Z. Navarro (org.). Agricultura brasileira: desempenho, desafios e perspectivas. Brasília, DF, IPEA: 157-184.

INSTITUTO PENSAR AGROPECUÁRIA. (2019), IPA: informação [08 abr. 2019]. Informação concedida ao autor.

KAGEYAMA, Angela et al. (1990), "O novo padrão agrícola brasileiro: do complexo rural aos complexos agroindustriais", in G. C. Delgado et al. (org.), Agricultura e politicas públicas. Brasília, DF, IPEA: 113-223.

MALASSIS, Louis. (1975), Groupes, complexes et combinats agro-industriels: méthods et concepts. Paris, ISMEA.

MENDONÇA, SONIA REGINA. (2008), "O Patronato Rural Brasileiro na Atualidade: dois estudos de caso". Anuario del Centro de Estudios Históricos Profesor Carlos S. A. Segreti, 8: 139-159.

MONTERO, Paula; ARRUTI, José Maurício; POMPA, Cristina. (2012), "Para uma antropologia do político”, in A. G. Lavalle (org.). O horizonte da política: questóes emergentes e agenda de pesquisa. São Paulo, Unesp: 145-184.

MONTERO, Paula. (2012), "Controvérsias religiosas e Esfera Pública: repensando as religiôes como discurso". Religião \& Sociedade, 32: 15-30.

MOYANO, Eduardo. (1985), "Syndicalisme et agriculture dans la transition démocratique en Espagne”. Économie Rurale, 168: 40-47.

MULLER, Geraldo. (1989), Complexo agroindustrial e modernização agrária. São Paulo, Hucitec.

PASSOS GUIMARÃES, Alberto. (1975), "O Complexo Agroindustrial”. Opinião, 21 nov.
POMPEIA, Caio. Formação Política do Agronegócio. (2018), (352 p.). Tese de Doutorado. Universidade Estadual de Campinas, Instituto de Filosofia e Ciências Humanas, Harvard University, Campinas, SP.

POMPEIA, Caio. (2020), “'Agro é tudo': simulaçôes no aparato de legitimação do agronegócio”. Horiz. antropol., Porto Alegre, v. 26, n. 56, abril: 195-224.

RAMOS, Pedro. (2007), "Referencial teórico e analítico sobre a agropecuária brasileira", in P. Ramos (org.). Dimensóes do Agronegócio Brasileiro: Políticas, Instituiçóes e Perspectivas. Brasília, NEAD Estudos, 1: 18-52.

SAUER, Sérgio; LEITE, Sergio Pereira. (2012), "Expansão agrícola, preços e apropriação de terra por estrangeiros no Brasil”. Revista de Economia e Sociologia Rural, 50, 3: 503-524.

SAUER, Sérgio; BORRAS JR., Saturnino. (2016), “ 'Land grabbing' e 'green grabbing': Uma leitura da 'corrida na produção acadêmica' sobre a apropriação global de terra”. Campo-Território. Edição especial, junho: 6-42.

SOCIEDADE NACIONAL DE AGRICULTURA. (2015), Mapa cria Fórum das Entidades Representativas do Agronegócio. Disponível em: $<$ https://www.sna.agr.br/mapa-cria-forum-dasentidades-representativas-do-agronegocio/>. Acesso em: 31 mai. 2019.

TACHARD, Guy. (1687), Dictionarium novum Latino-Gallicum. Paris, A. Prallard.

TAVARES, Vinícius. (2018), A História da Bancada Ruralista - Personagens e fatos que tornaram a Frente Parlamentar da Agropecuária protagonista do sucesso do agronegócio brasileiro. Brasília, DF, Vincere.

VIGNA, Edélcio. (2001), A bancada ruralista: um grupo de interesse. Brasília, INESC. 


\section{CONCERTAÇÁO E PODER O AGRONEGÓCIO COMO FENÔMENO POLÍTICO NO BRASIL}

\section{Caio Pompeia}

Palavras-chave: Agronegócio; Concertação; Justificação; Conflitos.

Em função do acirramento de disputas fundiárias e conflitos socioambientais, em anos recentes, agentes do campo do agronegócio no Brasil impulsionaram, de modo organizado e sistemático, sua concertação política. Argumenta-se, no presente artigo, que esse processo de orquestraçáo engendrou um novo padrão de representatividade nesse campo, mais apto a operar no âmbito de questóes amplas, como a ambiental, a indígena e a trabalhista. Propondo um conceito para caracterizar esse padrão, o artigo historiciza o movimento de aproximação política entre tais agentes, aborda seu aparato de justificaçáo, examina conflitos entre eles e investiga os dispositivos que empregam para racionalizar o tratamento das divergências e promover acordos. A pesquisa é fundamentada em oito meses de trabalho de campo, sobretudo no Instituto Pensar Agropecuária, no Congresso Nacional e na sede da Confederação da Agricultura e Pecuária do Brasil.

\section{CONCERTATION AND POWER: AGRIBUSINESS AS A POLITICAL PHENOMENON IN BRAZIL}

\section{Caio Pompeia}

Keywords: Agribusiness; Concertation; Justification; Conflicts.

Due to the intensification of land disputes and socio-environmental conflicts in recent years, agribusiness agents in Brazil have expanded their political concertation in an organized and systematic manner. In this article, it is argued that this orchestration process engendered a new representativeness pattern in this field, better able to operate in the scope of broad issues such as environmental, indigenous, and labor topics. Proposing a concept to characterize this pattern, this article historicizes the political approximation movement between these agents, addresses their justificatory apparatus, examines conflicts and investigates the devices they employ to rationalize divergence handling and promote agreements. The research is based on eight months of fieldwork, mainly at the Instituto Pensar Agropecuária, within the Brazilian National Congress, and the headquarters of the Brazilian Agriculture and Ranching Confederation.

\section{CONCERTATION ET POUVOIR: L'INDUSTRIE AGROALIMENTAIRE EN TANT QUE PHENOMENE POLITIQUE AU BRESIL}

\section{Caio Pompeia}

Mots-clés: Industrie agroalimentaire; concertation; justification; conflits.

Avec l'intensification récente des conflits fonciers et socio-environnementaux, les acteurs de l'industrie agroalimentaire brésilienne ont organisé de manière systématique leur concertation politique. Un tel processus a donné lieu à une nouvelle norme de représentativité capable de faire face à des questions plus vastes, à l'exemple de celles portant sur l'environnement, les Amérindiens ou le travail. À partir d'un concept caractéristique de cette norme, l'article examine le rapprochement politique entre les acteurs, leur justification, les conflits et les moyens utilisés pour résoudre les divergences et promouvoir des accords. La recherche se base sur huit mois de travail sur le terrain, principalement à l'Institut Pensar Agropecuária, au Congrès National et au siège de la Confédération brésilienne de l'Agriculture et de l'Élevage. 